\title{
Prevalence of Pulmonary Disorders in Patients with End Stage Renal Disease on Hemodialysis
}

\author{
Ahmed E Kabil ${ }^{1}$, Fareed Shawky Basiony ${ }^{1}$, Mohamed Osama Nour ${ }^{2}$, Khaled S. Makboul ${ }^{3}$ \\ ${ }^{1}$ Department of Chest Diseases, Faculty of Medicine, Al-Azhar University, Egypt \\ ${ }^{2}$ Department of Public Health and Community Medicine, Al-Azhar Faculty of Medicine, Damietta, Egypt, \\ Faculty of Public Health and Health Informatics, Umm AL Qura University, Makkah, KSA. \\ ${ }^{3}$ Department of Internal medicine, Faculty of Medicine, Al-Azhar University, Egypt \\ Corresponding author: Ahmed E Kabil, Mobile: 01006396601, Email: a_ka_81@hotmail.com
}

\begin{abstract}
Background: The prevalence of patients with end stage renal disease is increasing. Pulmonary diseases have been suggested to be more common in end stage renal disease patients on haemodialysis.

Aim of the work: It was to evaluate the pulmonary function state and the prevalence of pulmonary disorders in hemodialysis patients. Subjects and methods: A retrospective study on 61 patients with chronic renal failure on regular Hemodialysis at El-Hussein University Hospital, Al-Azhar University. Results: The study included 61 chronic renal failure patients fulfilling the inclusion criteria with mean age $54.23 \pm 10.07$ years that ranged from $26-77$ years old. Females represent $62.3 \%$, about one third of patients (31.15\%) were smokers and slightly more than half of them living in rural areas Pulmonary functions were affected in nearly half of them (restrictive $27.87 \%$, obstructive $14.75 \%$ and mixed $6.56 \%$ ). Variety of pulmonary disorders coexisted in about $69 \%$ of patients with $22.95 \%$ suffered from pleural effusion, $16.39 \%$ had $\mathrm{TB}, 11.48 \%$ and $8.20 \%$ developed pulmonary embolism and pulmonary edema respectively and finally community acquired pneumonia and uraemic asthma. Conclusion: Respiratory disorders especially restrictive lung pattern, pleural effusion, pneumonia and pulmonary embolism were associated with end stage renal disease on regular hemodialysis. Recommendation: Any patient with chronic renal failure, especially patients on regular hemodialysis should be observed early for detection of any pulmonary diseases or disorders.
\end{abstract}

Keywords: Renal failure, Hemodialysis, pulmonary disorders.

\section{INTRODUCTION}

Chronic kidney disease (CKD) is that type of kidney disorder in which there is gradual decline of kidney functions over a period of months up to years. It may be asymptomatic in early stages. Later, leg edeoma, tiredness, repeated vomiting, loss of appetite, or disturbed level of consciousness may develop. Complications may include cardiac diseases, elevated blood pressure, bone disorders, and anemia ${ }^{(\mathbf{1})}$. Chronic kidney disease affected about 753 million people worldwide in 2016, including 417 million females and 336 million males. In 2015, it resulted in 1.2 million deaths. While in 1990, 409,000 deaths were reported. The causes that contribute to that large number of deaths included high blood pressure at 550,000, followed by diabetes at 418,000, and glomerulonephritis at $238,000^{(2)}$. Different pulmonary abnormalities, including pulmonary edema, pleural effusion, acute respiratory distress syndrome, pulmonary fibrosis and calcification, pulmonary hypertension, haemosiderosis, pleural fibrosis, and sleep apnea syndrome, have been reported in these patients ${ }^{(3)}$.

Impaired pulmonary function may be precipitated by the direct effect of circulating uremic toxins or may be indirectly caused by fluid overload, anemia, immune suppression, extraosseous calcification, malnutrition, electrolyte disorders, and/or acid-base imbalances, which are common issues in hemodialysis patients ${ }^{(4)}$.
Fluid overload, together with the marked increase in pulmonary capillary permeability can result in pulmonary edema and pleural effusion, abnormalities that may explain, at least in part, the decline in pulmonary functions. Since hemodialysis help in removing excess body fluid, it can also lead to improvement in pulmonary functions by decreasing the water content of both lungs ${ }^{(5)}$.

\section{SUBJECT AND METHODS}

The present study was a descriptive, retrospective study that conducted at El-Hussein University Hospital, Cairo, Egypt. 61 patients, referred for Chest Department for evaluation for any pulmonary disorders during the period from January 2016 to June 2017, were included in the current study. All patients were with end stage renal disease on hemodialysis. The study was approved by the Hospital Ethical Committee and a written consent was obtained from each patient prior to the procedure. All patients were subjected to the following: Full history taking, physical examination, plain chest $\mathrm{x}$-ray: (postero-anterior and lateral views), complete blood picture, liver and kidney function tests, arterial blood gases, pulmonary function test and CT chest if needed for confirming the diagnosis of the pulmonary complications. All medical records of the patients were retrospectively revised.

Inclusion criteria: All patients had end stage renal disease and on hemodialysis. 
Exclusion criteria: The following patients werw excluded from the study: hemodynamically unstable patients, pregnancy, known cardiovascular disease, patients with chronic lung disease, such as COPD, bronchial asthma and interstitial lung diseases.

\section{Statistical analysis}

Statistical analysis was done using the SPSS computer package, version 19.0 (SPSS Inc., Chicago, Illinois, USA). For descriptive statistics, the mean \pm SD was used for quantitative variables while the number and percentage were used for qualitative variables. In univariate analyses, the qualitative variables were compared by $\chi 2$-test or Fischer's exact test when appropriate and the quantitative variables were compared by independent samples t-test. Sensitivity, specificity, accuracy, and positive and negative predictive values were calculated for the determination of tube placement. The statistical methods were verified, assuming a significant level of $P$ value of less than 0.05 and a highly significant level of $\mathrm{P}$ value of less than 0.001 .

\section{RESULTS}

The study included 61 chronic renal failure patients fulfilling the inclusion criteria with mean age $54.23 \pm$ 10.07 years that ranged from $26-77$ years old. Females represent $62.3 \%$, about one third of patients (31.15\%) were smokers and slightly more than half of them living in rural areas (Table 1).

Table (1): General characteristics of the studied sample

\begin{tabular}{|l|l|c|c|}
\hline \multicolumn{2}{|c|}{ Variables } & \multicolumn{2}{c|}{ No=6 $\%$} \\
\hline Age (year) & Mean \pm SD Min & \multicolumn{2}{|c|}{$54.23 \pm 10.07$} \\
& Max & \multicolumn{2}{c|}{$26.0-77.0$} \\
\hline \multirow{2}{*}{ Gender } & Male & 23 & 37.70 \\
\cline { 2 - 4 } & Female & 38 & 62.30 \\
\hline \multirow{2}{*}{ Smoking } & Smoker & 19 & 31.15 \\
\cline { 2 - 4 } Habit & Non-smoker & 42 & 68.85 \\
\hline \multirow{2}{*}{ Residence } & Urban & 29 & 47.54 \\
\cline { 2 - 4 } & Rural & 32 & 52.46 \\
\hline
\end{tabular}

About $29.5 \%$ of patients were overweight and obese, comorbidity existed in about $73.8 \%$ of them (HTN $19.67 \%$, DM 27.87\% and CLD 26.23\%) as shown in table 2).

Table (2): Clinical characteristics of the studied sample

\begin{tabular}{|l|l|l|l|}
\hline \multicolumn{2}{|c|}{ Variables } & \multicolumn{1}{c|}{ No=61 } & $\%$ \\
\hline \multirow{4}{*}{ BMI } & Normal & 29 & 47.54 \\
\cline { 2 - 4 } & Under weight & 14 & 22.95 \\
\cline { 2 - 4 } & Over weight & 9 & 14.75 \\
\cline { 2 - 4 } & Obese & 9 & 14.75 \\
\hline \multirow{3}{*}{$\begin{array}{c}\text { Co- } \\
\text { morbidity }\end{array}$} & HTN & 12 & 19.67 \\
\cline { 2 - 4 } & DM & 17 & 27.87 \\
\cline { 2 - 4 } & CLD & 16 & 26.23 \\
\cline { 2 - 4 } & No & 16 & 26.23 \\
\hline
\end{tabular}

About $44.26 \%$ of patients were on regular dialysis for a period of $6-12$ months and $27.87 \%$ were either less than 6 months or more than 12 months. Whereas, nearly one third of them $(32.79 \%)$ underwent dialysis once weekly (Table 3).

Table (3): Duration and frequency of dialysis of the studied sample

\begin{tabular}{|l|l|c|l|}
\hline \multicolumn{1}{|c|}{ Variables } & No=61 & $\%$ \\
\hline \multirow{3}{*}{$\begin{array}{c}\text { Duration } \\
\text { of dialysis }\end{array}$} & $<6$ months & 17 & 27.87 \\
\cline { 2 - 4 } & $6-12$ months & 27 & 44.26 \\
\cline { 2 - 4 } & $>12$ months & 17 & 27.87 \\
\hline \multirow{3}{*}{$\begin{array}{c}\text { Frequency } \\
\text { of dialysis }\end{array}$} & Once weekly & 20 & 32.79 \\
\cline { 2 - 4 } & 2 times / week & 17 & 27.87 \\
\cline { 2 - 4 } & 3 times / week & 24 & 39.34 \\
\hline
\end{tabular}

Pulmonary functions were affected in nearly half of them (restrictive $27.87 \%$, obstructive $14.75 \%$ and mixed $6.56 \%)$. Variety of pulmonary disorders coexisted in about $69 \%$ of patients with $22.95 \%$ suffered from pleural effusion, $16.39 \%$ had TB and $11.48 \%$ and $8.20 \%$ developed pulmonary embolism and pulmonary edema respectively. Finally, community acquired pneumonia and bronchial asthma (4.92\% each) as shown in table 4).

Table (4): Clinical characteristics of the studied sample

\begin{tabular}{|l|l|l|l|}
\hline \multicolumn{2}{|r|}{ Variables } & No=6 & $\%$ \\
\hline \multirow{4}{*}{$\begin{array}{l}\text { Pulmonary } \\
\text { function }\end{array}$} & Restrictive & 17 & 27.87 \\
\cline { 2 - 4 } & Obstructive & 9 & 14.75 \\
\cline { 2 - 4 } & Mixed & 4 & 6.56 \\
\cline { 2 - 4 } & Normal & 31 & 50.82 \\
\hline
\end{tabular}

Variety of pulmonary disorders coexisted in about $69 \%$ of patients with $22.95 \%$ suffered from pleural effusion, $16.39 \%$ had TB and $11.48 \%$ and $8.20 \%$ developed pulmonary embolism and pulmonary edema respectively. Finally, community acquired pneumonia and ureamic asthma (4.92\% each) as shown in table 5).

Table (5): Clinical characteristics of the studied sample

\begin{tabular}{|l|l|l|l|}
\hline \multicolumn{2}{|c|}{ Variables } & No=61 & $\%$ \\
\hline \multirow{4}{*}{$\begin{array}{l}\text { Pulmonary } \\
\text { disorders }\end{array}$} & Pulmonary edema & 5 & 8.20 \\
\cline { 2 - 4 } & TB & 3 & 4.92 \\
\cline { 2 - 4 } & Pleural effusion & 14 & 22.95 \\
\cline { 2 - 4 } & Pulmonary embolism & 7 & 11.48 \\
\cline { 2 - 4 } & $\begin{array}{l}\text { Community acquired } \\
\text { pn. }\end{array}$ & 10 & 16.39 \\
\cline { 2 - 4 } & Ureamic asthma & 3 & 4.92 \\
\cline { 2 - 4 } & No & 19 & 31.15 \\
\hline
\end{tabular}

Presence of pulmonary disorders among patients with chronic renal failure did not show significant relations with either age of patients, duration or frequency of dialysis. (Figure 1 and tables 6 and 7) 


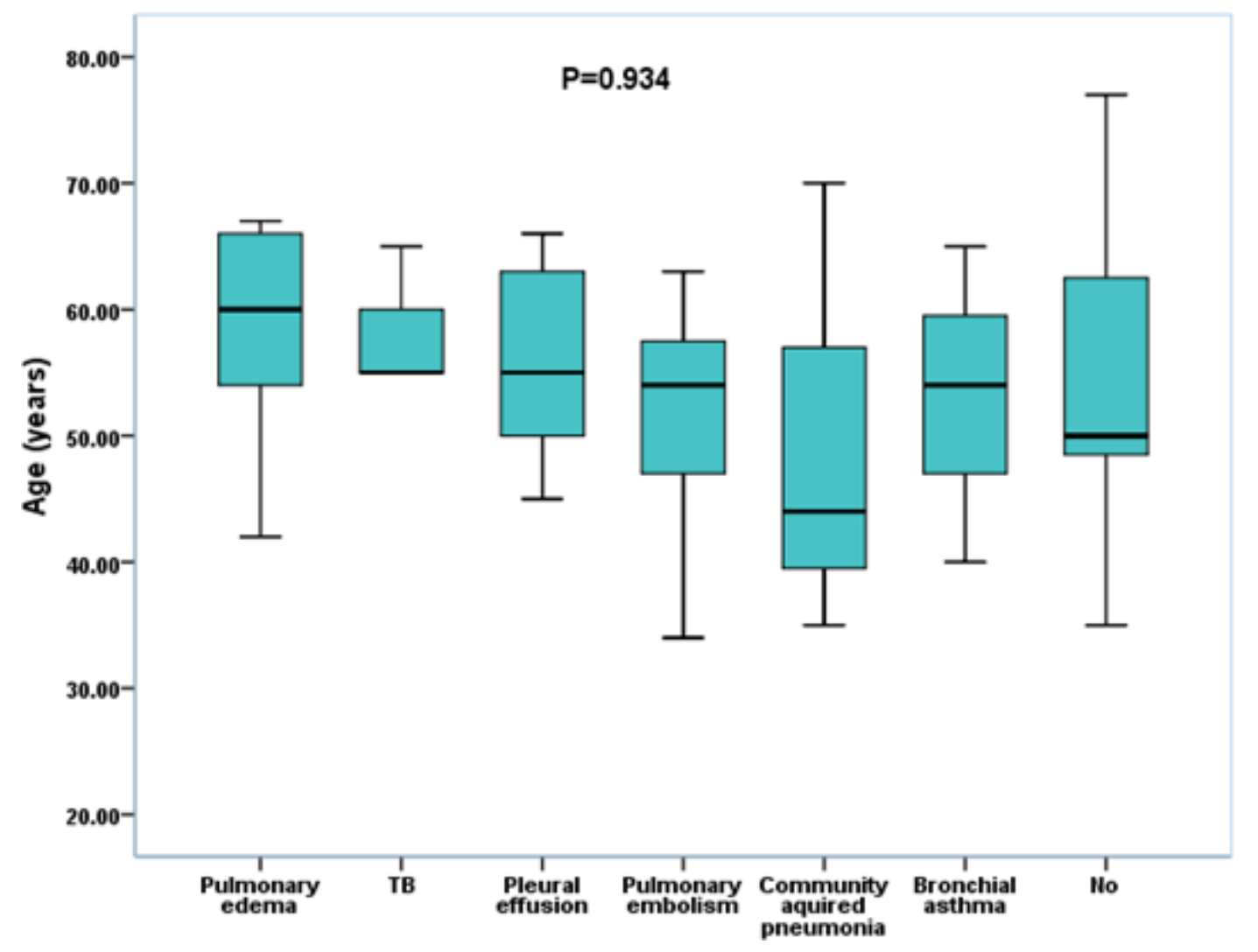

Figure (1): Mean age distribution according to pulmonary disorders of the studied sample.

Table (6): Duration of dialysis according to pulmonary disorders of the studied sample

\begin{tabular}{|l|l|l|l|}
\hline \multirow{2}{*}{ Pulmonary disorders } & \multicolumn{2}{|l|}{ Duration of dialysis } \\
\cline { 2 - 4 } & $\begin{array}{c}<\text { months } \\
\mathrm{N}=17(\%)\end{array}$ & $\begin{array}{c}6-12 \text { months } \\
\mathrm{N}=27(\%)\end{array}$ & $\begin{array}{c}>12 \text { months } \\
\mathrm{N}=17(\%)\end{array}$ \\
\hline Pulmonary edema & $0(0.0)$ & $5(18.5)$ & $0(0.0)$ \\
\hline TB & $4(23.5)$ & $5(18.5)$ & $1(5.9)$ \\
\hline Pleural effusion & $6(35.3)$ & $4(14.8)$ & $4(23.5)$ \\
\hline Pulmonary embolism & $1(5.9)$ & $3(11.1)$ & $3(17.6)$ \\
\hline Community acquired pneumonia & $1(5.9)$ & $0(0.0)$ & $2(11.8)$ \\
\hline uraemic asthma & $2(11.8)$ & $0(0.0)$ & $1(5.9)$ \\
\hline No & $3(17.6)$ & $10(37.0)$ & $6(35.5)$ \\
\hline X2=18.34 & P-value $=0.106$ &
\end{tabular}

Values present as number and percent $\&$ analyzed by Chi-Square test.

Table (7): Frequency of dialysis according to pulmonary disorders of the studied sample

\begin{tabular}{|l|c|c|c|}
\hline \multirow{2}{*}{ Pulmonary disorders } & \multicolumn{2}{|c|}{ Frequency of dialysis } \\
\cline { 2 - 4 } & $\begin{array}{c}\text { Once weekly } \\
\mathrm{N}=20(\%)\end{array}$ & $\begin{array}{c}2 \text { times / week } \\
\mathrm{N}=17(\%)\end{array}$ & $\begin{array}{c}3 \text { times / week } \\
\mathrm{N}=24(\%)\end{array}$ \\
\hline Pulmonary edema & $0(0.0)$ & $4(23.5)$ & $1(4.2)$ \\
\hline TB & $3(15.0)$ & $1(5.9)$ & $6(25.0)$ \\
\hline Pleural effusion & $7(35.0)$ & $3(17.6)$ & $4(16.7)$ \\
\hline Pulmonary embolism & $2(10.0)$ & $2(11.8)$ & $3(12.5)$ \\
\hline Community acquired pneumonia & $1(5.0)$ & $1(5.9)$ & $1(4.2)$ \\
\hline Uraemic asthma & $1(5.0)$ & $0(0.0)$ & $2(8.3)$ \\
\hline No & $6(30.0)$ & $6(35.3)$ & $7(29.2)$ \\
\hline \multicolumn{3}{|c|}{ P2-value $=0.384$} \\
\hline
\end{tabular}

Values present as number and percent \& analyzed by Chi-Square test. 


\section{DISCUSSION}

ESRD is worldwide health problem that increases morbidity and mortality and decreases quality of live. Prevalence of ESRD increases with increase in rate of DM, HTN, obesity and old age ${ }^{(6)}$. Almost all body system adversely affected by ESRD, respiratory system is especially affected due to pulmonary complications, which increase in ESRD with hemodialysis ${ }^{(7)}$.

In our study, we found that respiratory complication among patients with ESRD on renal dialysis with predominant pleural effusion, which affect $22.95 \%$ of patient. Variable proportion of pleural effusion have been reported in multiple study. Pleural effusion was previously reported in $16 \%{ }^{(8)}$ and $6.7 \%$ in another study ${ }^{(9)}$. The high incidence in our study may be because we exclude patients on Lasix and pleural effusion, which can be caused by multiple factors, which may be different from country to other.

In our study, pulmonary tuberculosis was $16,39 \%$ of patients might be because most of patients from rural area (52.46\% of the studied group).

In our study, community acquired pneumonia $4.92 \%$, which is far less than reported cases in other studies $14 \%{ }^{(8)}$ and $26 \%{ }^{(9)}$. Infection caused morbidity and mortality in most patient with CKD ${ }^{(11)}$.

Uraemic asthma (patient was bronchospasm without history of bronchial asthma that respond with correction of renal conditions) represented $4.92 \%$ of the studied group.

Pulmonary embolism affects $11.48 \%$ of the studied group. Pulmonary edema represented $8.20 \%$ of the studied group. Variable proportion of pulmonary edema have been reported in previous study $22 \%{ }^{(8)}$ and $36 \%{ }^{(10)}$, which is higher than our result. This variation may be due to high cardiovascular risk profile of patient with ESRD in that study, as cardiovascular disease, which is the main cause of pulmonary oedema ${ }^{(\mathbf{1 2})}$. In our study, we excluded patients with cardiovascular diseases. Pulmonary disorder coexist in $69 \%$ of the studied patients.

In our study, presence of pulmonary disorders among patients with chronic renal failure did not show significant relations with either age of patients, duration or frequency of dialysis. In other study, this complication increased with age ${ }^{(8)}$, as CKD is more common in elder. Decline in renal function with increase in age was established in many studies ${ }^{(13,14)}$. In addition, co morbidity as DM and HTN, the major risk of CKD are more common in elder ${ }^{(15)}$. This may be because most patients in our study had short duration of dialysis.

In our study, about $29.5 \%$ of patients were overweight and obese, co-morbidity existed in about $73.8 \%$ of them (HTN 19.67\%, DM 27.87\% and CLD 26.23\%).

Pulmonary functions were affected in nearly half of them (restrictive $27.87 \%$, obstructive $14.75 \%$ and mixed $6.56 \%$ ). These results are in agreement with many studies as Sharma et al. ${ }^{(16)}$ where they reported that pulmonary function abnormalities were common among end stage renal disease patients. They also reported that the majority of patients had restrictive and mixed respiratory disorders.

\section{CONCLUSION}

Our study concluded that variety of pulmonary disorders can affect patients with end stage renal disease as pleural effusion, community acquired pneumonia, TB, pulmonary embolism, pulmonary edema and uraemic asthma. Pulmonary functions abnormalities especially restrictive lung disorders are more common in patients with end stage renal disease on regular haemodialysis.

\section{RECOMMENDATION}

Patients with chronic renal failure, especially on hemodialysis should be observed as early as possible for detection of any pulmonary disorders.

\section{Financial support and sponsorship: Nil.}

Conflicts of interest: There are no conflicts of interest.

\section{REFERENCES}

1. Bikbov B, Perico N, Remuzzi G (2018): Disparities in Chronic Kidney Disease Prevalence among Males and Females in 195 Countries: Analysis of the Global Burden of Disease 2016 Study. Nephron, 139 (4): 31318.

2. Liao MT, Sung CC, Hung KC et al. (2012): Insulin Resistance in Patients with Chronic Kidney Disease. Journal of Biomedicine and Biotechnology, 2: $1-5$.

3. Navari K, Farshidi H, Pour-Reza-Gholi F et al. (2008): Spirometry parameters in patients undergoing hemodialysis with bicarbonate and acetate dialysates. Iran J Kidney Dis., 2 (3): 149-53.

4. Abdalla ME, AbdElgawad M, Alnahal A (2013): Evaluation of pulmonary function in renal transplant recipients and chronic renal failure patients undergoing maintenance hemodialysis. Egyptian Journal of Chest Diseases and Tuberculosis, 62 (1): 145-50.

5. Kovelis D, Pitta F, Probst VS et al. (2008): Pulmonary function and respiratory muscle strength in chronic renal failure patients on hemodialysis. J Bras Pneumol., 34 (11): 907-12.

6. Stevens LA, Viswanathan G, Weiner DE (2010): Chronic kidney disease and endstage renal disease in the elderly population: current prevalence, future projections, and clinical significance. Adv Chronic Kidney Dis., 17 (4): 293-301.

7. Kovelis D, Pitta F, Probst VS et al. (2008): Pulmonary function and respiratory muscle strength in chronic renal failure patients on hemodialysis. J Bras Pneumol., 34 (11): 907-12.

8. Alosayfir M, Almuzaini F, Alateeq $M$ et al. (2016): Assessment of Respiratory Complications Associated 


\section{ejhm.journals.ekb.eg}

with End Stage Renal Disease in Northern Saudi Arabia. Rom J Intern Med., 4: 237-242.

9. Ray S, Mukherjee S, Ganguly J et al. (2013): A crosssectional prospective study of pleural effusion among cases of chronic kidney disease. Indian $\mathbf{J}$ Chest Dis Allied Sci., 55 (4): 209-13.

10.Halle MP, Hertig A, Kengne AP et al. (2012): Acute pulmonary oedema in chronic dialysis patients admitted into an intensive care unit. Nephrol. Dial. Transplant., 27 (2): 603-607.

11. Viasus D, Garcia-Vidal C, Cruzado JM et al. (2011): Epidemiology, clinical features and outcomes of pneumonia in patients with chronic kidney disease. Nephrol Dial Transplant., 26(9):2899-906.
12. Levin A (2003): Clinical epidemiology of cardiovascular disease in chronic kidney disease prior to dialysis. Semin Dial., 16: 101-105.

13. Epstein M (1996): Aging and the kidney. J Am Soc Nephrol., 7 (8): 1106-22.

14. Orchardson RL (1966): Renal function and age. J Coll Gen Pract., 12 (3): 285-92.

15. Ginawi IA, Elasbali AM, Ahmed HG et al. (2013): Population screening for chronic kidney disease and its associated risk factors: a survey in Hail region, KSA. J Public Health Epidemiol., 5 (7): 285-90.

16. Sharma A, Sharma A, Gahlot S et al. (2017): A study of pulmonary function in end-stage renal disease patients on hemodialysis: a cross-sectional study. Sao Paulo Med J., 135 (6): 568-72. 